\title{
INVESTIGATION OF THE STABILITY OF THE ANTI-ISLANDING DETECTION IN MULTI-DGs SYSTEM
}

\author{
Weihua Chen, Xiaoheng Yan, Jishen Pen, Zhongjian Zhao
}

Original scientific paper This paper presents an improved model of multi-DGs microgrids for analysing system stability during grid-connections. The DGs-in the system are equipped with the Sandia frequency shift (SFS) scheme as an anti-islanding protection technique. By introducing a distribution network line length, SFS positive feedback gain and distributed power supply, power output parameters to improve the micro power grid mathematical model are established in three kinds of parameters and the relationship between micro power grid stability margin, to obtain stability of the system of power line length threshold, and stability of the distributed power dc output voltage threshold. This process allows the designers and engineers of renewable energy systems to optimize the system and ensure stability. Finally, in view of the several common simulation validations, this paper puts forward an improved model that can affect actual implementation of distributed micro power grid analysis, whereby the stability of the system parameters' critical threshold may be deduced. Based on these case studies, system stability is shown to be very important to the stability of many distributed multi-DGs microgrids, which are useful for the design and implementation of new energy systems.

Keywords: anti-islanding protection; multi-DGs microgrid; Sandia frequency shift; system parameters; system stability; threshold values

Istraživanje stabilnosti anti-islanding detekcije u multi-DGs sustavu

Izvorni znanstveni članak

U radu je predstavljen poboljšani model multi-DGs mikro rešetki za analizu stabilnosti sustava tijekom vezivanja s rešetkom. DGs u sustavu opremljeni su Sandia frequency shift (SFS) shemom kao načinom anti-islanding zaštite. Uvođenjem dužine linije distribucijske mreže, pozitivnog porasta povratne sprege SFSa i distribuiranog dovoda energije, parametri izlazne snage za poboljšanje matematičkog modela mikro energetskih rešetki uspostavljeni su u tri vrste parametara i odnosu između margine stabilnosti mikro energetske rešetke za postizanje stabilnosti sustava praga dužine linije energetske mreže, $i$ stabilnosti granične vrijednosti napona izlazne snage distribuirane istosmjerne struje. Taj postupak omogućuje projektantima i inženjerima obnovljivih energetskih sustava optimiziranje sustava i osiguranje stabilnosti. Konačno, uzimajući u obzir nekoliko potvrđivanja simulacija, u radu se daje poboljšani model koji može utjecati na aktualnu implementaciju analize distribuirane mikro energetske rešetke, te se tako može donijeti zaključak o stabilnosti kritičkog praga parametara sustava. Na temelju tih analiza slučaja, pokazalo se da je stabilnost sustava vrlo važna za stabilnost mikrorešetki mnogih distribuiranih multi-DGs, koji su korisni za projektiranje i implementaciju novih energetskih sustava.

Ključne riječi: anti-islanding zaštita; granične vrijednosti; mikrorešetka multi-DGs; parametri sustava; Sandia frequency shift; stabilnost sustava

\section{Introduction}

A multi-DGs system is a system in which a number of Distributed power Generations (DGs) are combined with technological advances in distribution electronic systems. Many types of DGs such as fuel-cells, PV cells and micro-turbines interface with the distribution electronic system through power electronic converters [1]. These interface devices make the DGs more flexible in operation and control compared to conventional electrical machines [2]. Islanding is a special class of faults in multi-DGs systems compared to traditional power grid faults. Islanding protection schemes can be categorized as: passive schemes [3], active schemes [4], and communication- based schemes [6].

The Sandia frequency shift (SFS) anti-islanding scheme is an attractive method for its small non-detection zones (NDZ). In recent publications, the effects of different factors on the SFS protection scheme's efficacy are considered separately. For instance, the impact of DG interface control on anti-islanding protection scheme and NDZ are investigated by Zeineldin and EI-Saadany in [6], three common DG interface controls (constant current control, constant PV control and constant PQ control) are discussed and the NDZ for the three interface controls is depicted at the end. The load characteristics affecting the performance of SFS anti-islanding protection scheme are examined in [7]. In their model, the load's frequency dependence parameter $\left(k_{\mathrm{pf}}\right)$ is introduced for determining the active power mismatch term for modelling NDZ, and the load and DG phase angle-frequency characteristic are presented under different loads' frequency dependence parameters and quality factors. The same study for load characteristics affecting the performance of SFS is carried out by Alaboudy in [8]; the main difference is that in this paper the $P-f$ and $Q-V$ droops are designed to drift simultaneously the reference active and reactive power for the DG interface controller in such a manner that creates an unstable post-islanding operation. The droops are based on the linear expression $P_{\text {ref }}=A \Delta f+P_{0}$ and $Q_{\text {ref }}=B \Delta V$; in addition, the slopes $\mathrm{A}$ and $\mathrm{B}$ should have different signs. Although the researchers have already carried out much research into studying the effects of different factors on the SFS, this research is limited to discussing the effect on a single DG; they do not consider multi-DGs systems, or the effect of system parameters, such as length of distribution line and DC voltage of DG, on system stability. In spite of some research about modelling and analysing what has been carried out $[9 \div 11]$, the authors analyse the effect of the feedback gain on DG location, DG number and substation capacitor etc. based on the $P-K$ curve in multi-DGs system [9], but are not able to quantify these effects.

This paper extends the research described in $[6 \div 9]$ and presents an improved model of multi-DGs system for DGs with Sandia frequency shift (SFS) anti-islanding protection schemes. Each DG system will have an interface controller and LC filter, which is designed to restrain the output harmonics of the inverter. The interface controller includes a phase angle shift, current 
control and voltage control. In order to analyse the effect of parameters like the length of the distribution line, and the DC voltage of the DG on the DG's stability, the model introduces the parameters of the length of distribution line $(L)$, DC voltage $\left(V_{\mathrm{dc}}\right)$ of $\mathrm{DG}$ and positive feedback gain $(k)$. Once the model is completed, the stability analysis of multi-DGs system can be finished based on the locus of the eigenvalues, and subsequently the threshold values of the length of the distribution line and DC voltage of DG can be obtained respectively. The relation between the system stability and the system parameters can be investigated further through the model.

The rest of this paper is organized as follows: Section 2 briefly introduces the principle of the anti-islanding scheme. In Section 3, the model of the multi-DGs system is completed, and then the stability of the multi-DGs system is analysed by using the locus of the eigenvalues in section 4. Section 5 validates the analysis results obtained from Section 4. Finally, conclusions about the paper and some suggestions for designers and engineers of renewable energy systems are given in section 6 .

\section{Principles of positive feedback of the anti-islanding scheme under study}

The frequency feedback scheme is a common method for anti-islanding protection. It uses the deviation of frequency at the point of common coupling (PCC) from normal values as a feedback signal to influence the output frequency of the inverter-based generator. When the generator operates in the islanding mode, the frequency will drift from nominal value, and islanding mode can be detected by under/over frequency relays. Sandia frequency shift (SFS) is one of the methods mentioned above, as shown in Fig. 1.

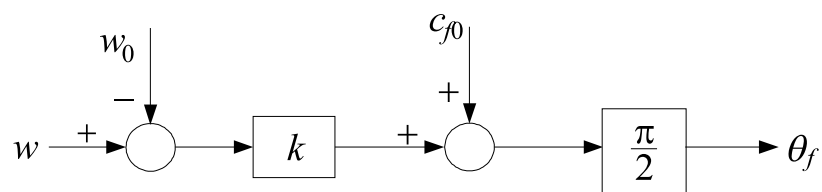

Figure 1 Block diagram of SFS

The detailed description of SFS can be found in [7]. The scheme is designed to add a force to destabilize the islanded DGs when the grid is disconnected. Due to the fact that converters with low inertia tend to make multiDGs systems sensitive to disturbances [12], it is critical to study the stability in a multi-DGs system. Previous research concerning SFS is based on the hypothesis that the destabilizing force is small and has little impact on DG stability when it is connected to the grid. However, when many DGs are combined in a distribution grid, the interaction will amplify the destabilizing force and thus lead the system to become unstable. In order to analyse the interaction quantitatively in multi-DGs systems, this paper will study the stability of multi-DGs systems with SFS anti-islanding protection during grid-parallel connection, by building a small signal model of multiDGs system. The principle of SFS can be expressed as an Eq. (1), $\theta_{f}=\frac{\pi}{2}\left(c_{f 0}+k\left(w-w_{0}\right)\right)$

where $\theta_{f}$ is the SFS transformation angle, $c_{f 0}$ is the chopping factor when there is no rotating frequency error and $\omega-\omega_{0}$ is the difference between the estimated rotating frequency and nominal rotating frequency.

\section{Model of multi-DGs system}

Consider a distributed grid in Fig. 2 with a multiple DGs system. In this figure, the resistance and the inductance of the distribution line 1 and line 2 are RL and $\mathrm{XL}$ respectively. The multiple DGs system is connected with the main grid through $\mathrm{CB}$. Each DG is connected with a distribution line through CBs.

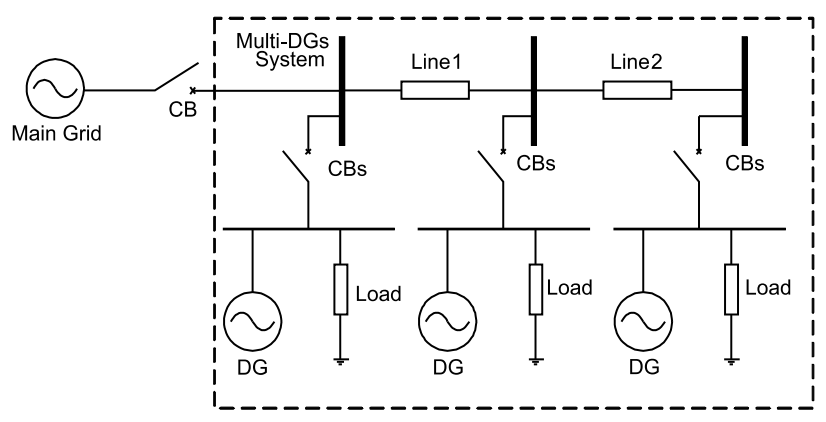

Figure 2 Multi-DGs system under consideration

The modelling approach can be found in [11], [13] and [14]. However, existing modelling methods about multiple DGs system are not available to DGs, which are equipped with anti-islanding protection. The whole system is divided into three parts: DGs, distribution grid and loads (Fig. 3).

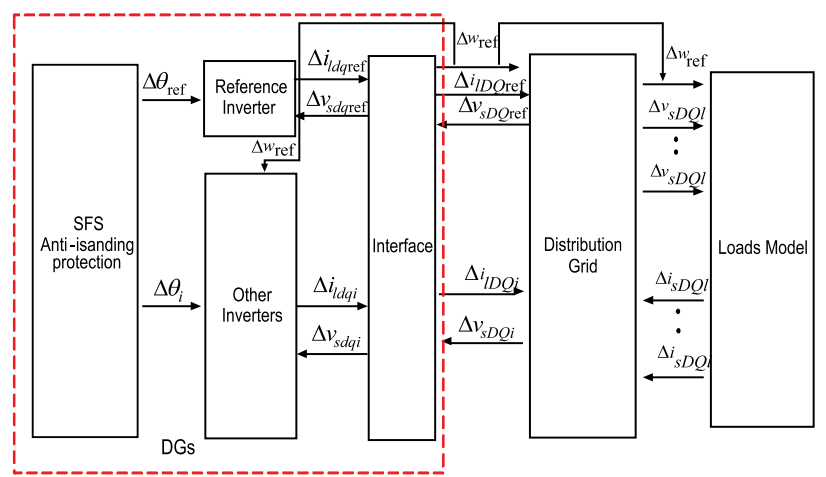

Figure 3 Interconnection block diagram of the Multi-DGs system

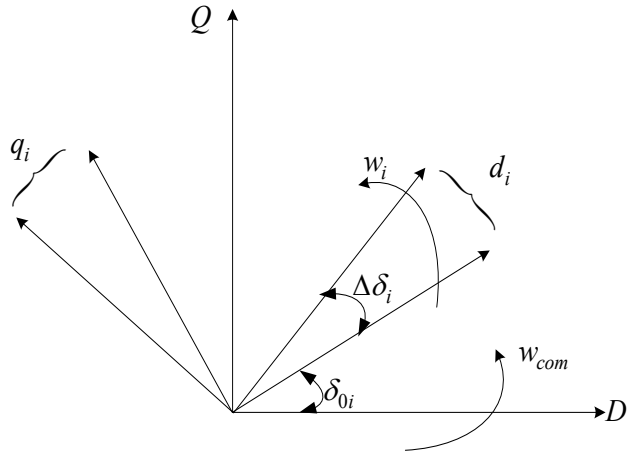

Figure 4 Reference frame transformation 
The DGs model includes the interface controller, and output filter. It is worth noting that each DG is modelled on its individual reference frame whose rotation frequency is set by its local interface controller. In order to retain synchronization, the DGs model needs to be translated to this common reference frame using the transformation technique [11] shown in Fig. 4. (3).

The transformation equations are defined in (2) and

$$
\begin{aligned}
& {\left[\Delta i_{s D Q}\right]=T_{i}\left[\Delta i_{s d q}\right]+T_{c}\left[\Delta \delta_{i}\right],} \\
& {\left[\Delta v_{s d q}\right]=T_{i}^{-1}\left[\Delta v_{s D Q}\right]+T_{v}\left[\Delta \delta_{i}\right],}
\end{aligned}
$$

where

$$
\begin{aligned}
& T_{i}=\left[\begin{array}{cc}
\cos \delta_{0 i} & \sin \delta_{0 i} \\
-\sin \delta_{0 i} & \cos \delta_{0 i}
\end{array}\right], \\
& T_{c}=\left[\begin{array}{c}
-\sin \delta_{0 i} I_{s d 0}+\cos \delta_{0 i} I_{s q 0} \\
-\cos \delta_{0 i} I_{s d 0}-\sin \delta_{0 i} I_{s q 0}
\end{array}\right], \\
& T_{v}=\left[\begin{array}{c}
-\sin \delta_{0 i} I_{s D 0}-\cos \delta_{0 i} I_{s Q 0} \\
\cos \delta_{0 i} I_{s D 0}-\sin \delta_{0 i} I_{s Q 0}
\end{array}\right],
\end{aligned}
$$

the Eqs. (2) and (3) are the positive translation and negative translation. $\delta_{0 i}$ is the steady-state angle between DGi and common reference frame. $\Delta \delta_{i}$ is the small increment of the angle between DGi and the common reference frame. $I_{s d 0}$ and $I_{s q 0}$ are the steady-state current is $d$ - $q$ components of DGi, and $I_{s D 0}$ and $I_{s Q 0}$ are the steadystate current in $d-q$ components of reference DG.

\subsection{Model of signal distributed power generation}

Fig. 5 shows the internal structure of DGs in Fig. 2. In this figure, the Renewable Energy Resources (e.g. solar cells) are replaced by a DC source $V_{\mathrm{dc}}$. The DG delivers power to the local load, which is represented by a parallel RLC load. The voltage and current of DGs is $V_{i}$ and $i_{i}$ respectively. The voltage and current of PCC is $V_{p}$ and $i_{l}$ respectively. The injection current of DG to the main grid is $i_{s}$. The node voltage of DGs connected with main grid is $V_{s}$.

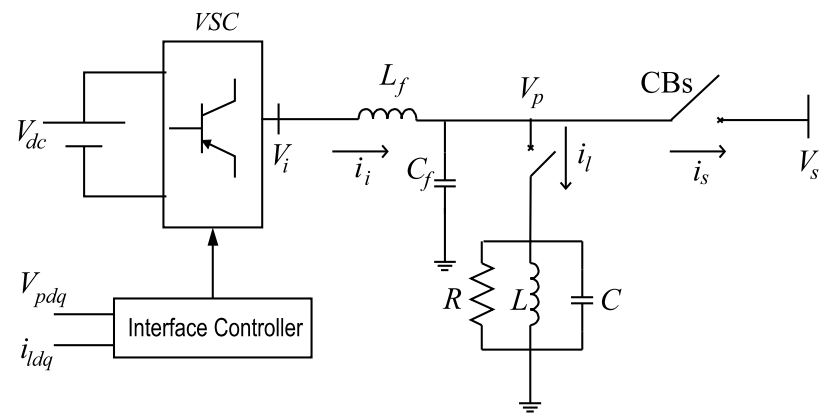

Figure 5 The interface controller of DGs

1) Interface Controller: As shown in Fig. 6, the $d$ and $q$ axis components of the load current are the shifted angle $\theta_{f}$ by the technology defined in (4). The $\Delta$ represents the small incremental of the $d$ and $q$ axis components of the load current, and the 0 represents the steady-state value.
$\left[\begin{array}{c}\Delta i_{l d}^{*} \\ \Delta i_{l q}^{*}\end{array}\right]=T_{i}\left[\begin{array}{c}\Delta i_{l d} \\ \Delta i_{l q}\end{array}\right]+T_{0} \Delta Q_{f}$

where

$$
\begin{aligned}
& \Delta Q_{f}=\frac{\pi}{2} k \Delta w, \quad T_{i}=\left[\begin{array}{cc}
\cos \theta_{f 0} & \sin \theta_{f 0} \\
-\sin \theta_{f 0} & \cos \theta_{f 0}
\end{array}\right], \\
& T_{0}=\left[\begin{array}{l}
-\sin \theta_{f 0} I_{l d 0}+\cos \theta_{f 0} I_{l q 0} \\
-\cos \theta_{f 0} I_{l d 0}-\sin \theta_{f 0} I_{l q 0}
\end{array}\right],
\end{aligned}
$$

load current, and then the error control is achieved with a standard PI controller. The corresponding equations are

$$
\left[\begin{array}{c}
\Delta v_{p d}^{*} \\
\Delta v_{p q}^{*}
\end{array}\right]=C_{i}\left[\begin{array}{c}
\Delta \gamma_{d} \\
\Delta \gamma_{q}
\end{array}\right]+D_{i 1}\left[\begin{array}{c}
\Delta i_{l d}^{*} \\
\Delta i_{l q}^{*}
\end{array}\right]+D_{i 2}\left[\begin{array}{c}
\Delta i_{l d} \\
\Delta i_{l q}
\end{array}\right],
$$

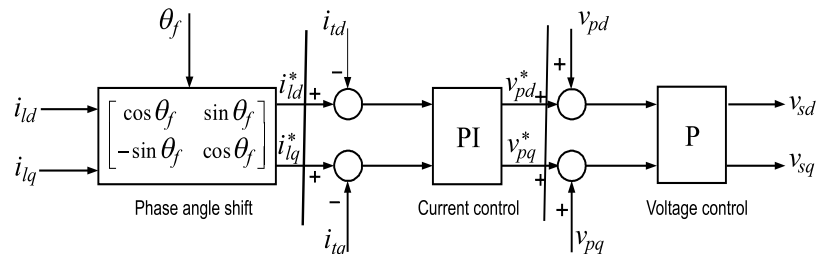

Figure 6 The interface controller of DGs

where

$$
\begin{aligned}
& \frac{\mathrm{d} \gamma_{d}}{\mathrm{~d} t}=i_{l d}^{*}-i_{l d}, \frac{\mathrm{d} \gamma_{q}}{\mathrm{~d} t}=i_{l q}^{*}-i_{l q}, \\
& C_{i}=\left[\begin{array}{cc}
K_{i i} & 0 \\
0 & K_{i i}
\end{array}\right], D_{i 1}=\left[\begin{array}{cc}
K_{p i} & 0 \\
0 & K_{p i}
\end{array}\right], D_{i 2}=\left[\begin{array}{cc}
-K_{p i} & 0 \\
0 & -K_{p i}
\end{array}\right] .
\end{aligned}
$$

Similarly, the voltage of PCC control is achieved with a stan- dard $\mathrm{P}$ controller. The corresponding equations are

$\left[\begin{array}{c}\Delta v_{s d} \\ \Delta v_{s q}\end{array}\right]=D_{v 1}\left[\begin{array}{c}\Delta v_{p d}^{*} \\ \Delta v_{p q}^{*}\end{array}\right]+D_{v 2}\left[\begin{array}{c}\Delta v_{p d} \\ \Delta v_{p q}\end{array}\right]$,

where

$D_{v 1}=D_{v 2}=\left[\begin{array}{cc}k_{p v} & 0 \\ 0 & k_{p v}\end{array}\right]$.

2) Output filter: The output filter in Fig. 5 is s device which can filter the high harmonics of the output current. Its model can be represented with the following equations by assuming that the inverter produces the demanded voltage $\left(v_{i}=v_{i}^{*}\right)$. Rotating frequency $\omega_{0}$ is the system steady-state rotating frequency at a given operating point.

$$
\begin{aligned}
& {\left[\begin{array}{c}
\Delta \dot{i}_{l d q} \\
\Delta \dot{v}_{p d q} \\
\Delta \dot{i}_{s d q}
\end{array}\right]=A_{L C}\left[\begin{array}{c}
\Delta i_{l d q} \\
\Delta v_{p d q} \\
\Delta i_{s d q}
\end{array}\right]+B_{L C 1}\left[\Delta v_{i d q}\right]+} \\
& +B_{L C 2}\left[\Delta v_{s d q}\right]+B_{L C 3}[\Delta w],
\end{aligned}
$$

where 


$$
\begin{aligned}
& \boldsymbol{A}_{L C}=\left[\begin{array}{cccccc}
-\frac{R_{f}}{L_{f}} & w_{0} & -\frac{1}{L_{f}} & 0 & 0 & 0 \\
-w_{0} & -\frac{R_{f}}{L_{f}} & 0 & -\frac{1}{L_{f}} & 0 & 0 \\
\frac{1}{C_{f}} & 0 & 0 & w_{0} & -\frac{1}{C_{f}} & 0 \\
0 & \frac{1}{C_{f}} & w_{0} & 0 & 0 & -\frac{1}{C_{f}} \\
0 & 0 & \frac{1}{L_{c}} & 0 & -\frac{R_{c}}{L_{c}} & w_{0} \\
0 & 0 & 0 & \frac{1}{L_{c}} & -w_{0} & -\frac{R_{c}}{L_{c}}
\end{array}\right], \\
& \boldsymbol{B}_{L C 1}=\left[\begin{array}{cccccc}
\frac{1}{L_{f}} & 0 & 0 & 0 & 0 & 0 \\
0 & \frac{1}{L_{f}} & 0 & 0 & 0 & 0
\end{array}\right]^{\mathrm{T}}, \\
& \boldsymbol{B}_{L C 2}=\left[\begin{array}{cccccc}
0 & 0 & 0 & 0 & \frac{1}{L_{f}} & 0 \\
0 & 0 & 0 & 0 & 0 & \frac{1}{L_{f}}
\end{array}\right]^{\mathrm{T}}, \\
& \boldsymbol{B}_{L C 3}=\left[\begin{array}{llllll}
I_{l q 0} & -I_{l d 0} & v_{p q 0} & -v_{p q 0} & I_{s q 0} & -I_{s d 0}
\end{array}\right] \text {. }
\end{aligned}
$$

It is assumed here that the controller's performance is perfect and hence, $v_{i}$ can be expressed as

$$
\Delta v_{i d q}=\Delta u_{d q} V_{d c}
$$

In (8), the $\mu$ is the control law, and $V_{d c}$ is dc voltage.

In order to achieve the control variables that can track the reference, the control law is expressed as

$u=-K\left[x-x_{\text {ref }}\right]$,

where

$$
X=\left[\begin{array}{lll}
i_{l d q} & v_{p d q} & i_{s d q}
\end{array}\right]^{\mathrm{T}}, K=\left[\begin{array}{lll}
K_{1} & K_{2} & K_{3}
\end{array}\right]^{\mathrm{T}} .
$$

So the control law of DG can be expressed in detail as

$u_{d q}=-K_{1}\left(i_{l d q}-i_{l d q \text { ref }}\right)-K_{2}\left(v_{l d q}-v_{l d q \text { ref }}\right)-$

$-K_{3}\left(i_{s d q}-i_{s d q \text { ref }}\right)$,

then

$$
\begin{aligned}
& \Delta v_{i d q}=\Delta u_{d q} V_{d c}= \\
& =\left(-K_{1} \Delta i_{l d q}-K_{2} \Delta v_{p d q}-K_{3} \Delta i_{s d q}\right) \cdot V_{d c}=-K \Delta x V_{d c},
\end{aligned}
$$

Substituting Eq. (11) into Eq. (7), the Eq. (7) can be expressed as

$$
\left[\begin{array}{c}
\Delta \dot{i}_{l d q} \\
\Delta \dot{v}_{p d q} \\
\Delta \dot{i}_{s d q}
\end{array}\right]=\left(A_{L C}-K V_{d c}\right) \cdot\left[\begin{array}{c}
\Delta i_{l d q} \\
\Delta v_{p d q} \\
\Delta i_{s d q}
\end{array}\right]+B_{L C 2}\left[\Delta v_{s d q}\right]+B_{L C 3}[\Delta w]
$$

Remark: In spite of the model presenting many aspects, such as [11] and [15], other DGs are translated to this common reference frame with the model equation (12). Using the transformation technique introduced in (2) and (3), the transferred model of DGi can be expressed as introducing the voltage of $\mathrm{DG}$, represented as $V_{d c}$, to analyse the relationship between the parameter $V_{d c}$ and the stability of the system. This is not considered in the existing research. Moreover the Eq. (12) also considers the positive feedback with anti-islanding protection equipped in DGs, represented as $K$. Therefore the model can analyse the unstable factors introduced by the antiislanding protection, which is necessary for gridconnected DGs.

3) Complete Model of Signal DG: A complete model of DG can be obtained by combining the Eqs. (4), (5), (7) and (12). The model equation can be expressed as

$\dot{x}_{\mathrm{INV}}=A_{\mathrm{INV}} x_{\mathrm{INV}}+B_{\mathrm{INV} 2}\left[\Delta v_{s d q}\right]+B_{\mathrm{INV} 3}[\Delta w]$,

where

$$
\begin{aligned}
& x_{\mathrm{INV}}=\left[\begin{array}{llll}
\Delta \gamma_{d q} & \Delta i_{l d q} & \Delta v_{p d q} & \Delta i_{s d q}
\end{array}\right]^{\mathrm{T}} \text {, }
\end{aligned}
$$

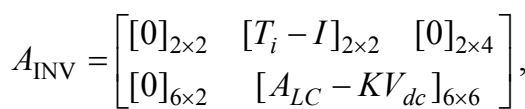

$$
\begin{aligned}
& B_{\mathrm{INV} 2}=\left[[0]_{2 \times 2} \quad\left[B_{L C 2}\right]_{6 \times 2}\right] \text {, } \\
& B_{\mathrm{INV} 3}=\left[\left[\frac{\pi}{2} k T_{0}\right]_{1 \times 2}^{\mathrm{T}} \quad\left[B_{L C 3}\right]_{1 \times 6}^{\mathrm{T}}\right] \text {. }
\end{aligned}
$$

4) Multi-DG Combination: as discussed earlier, the model of the signal DG needs to be translated to this common frame. In this paper, the DG1 is selected as the common reference frame, whose rotating frequency is $\omega_{\text {ref, }}$ and all the

$$
\begin{aligned}
& \dot{\tilde{\widetilde{x}}}_{\mathrm{INV} i}=A_{i} \tilde{\mathrm{x}}_{\mathrm{INV} i}+B_{1 i}\left[\Delta v_{s D Q}\right]+B_{2 i}[\Delta w], \\
& {\left[\Delta i_{s D Q}\right]=C_{i} \dot{\overrightarrow{\widetilde{x}}}_{\mathrm{INV} i},}
\end{aligned}
$$

where

$$
\begin{aligned}
& \tilde{x}_{\mathrm{INV} i}=\left[\begin{array}{ll}
\Delta \delta & x_{\mathrm{INV} i}
\end{array}\right]^{\mathrm{T}} \text {, } \\
& A_{i}=\left[\begin{array}{cc}
0 & {[0]_{1 \times 8}} \\
{\left[B_{\mathrm{INV} i 2} T_{v}\right]_{8 \times 1}} & {\left[A_{\mathrm{INV} i}\right]_{8 \times 8}}
\end{array}\right], \\
& B_{1 i}=\left[[0]_{1 \times 2} \quad\left[B_{\mathrm{INV} i 2} T_{i}^{-1}\right]_{8 \times 2}\right] \text {, } \\
& \left.B_{2 i}=\left[\begin{array}{ll}
1 & {\left[B_{\mathrm{INV} i 3}\right.}
\end{array}\right]_{8 \times 1}\right] \text {, } \\
& C_{i}=\left[\begin{array}{lll}
{\left[T_{c}\right]_{2 \times 1}} & {[0]_{2 \times 6}} & {\left[T_{i}\right]_{2 \times 2}}
\end{array}\right] \text {. }
\end{aligned}
$$

Consider a multi-DGs system with $n$ number of DG where the reference frame of DG1 is taken as the common reference frame. Then, from the transferred DG model as shown in Eqs. (16) and (17), a combined model of all DG in multi-DGs system is obtained, as shown in

$$
\begin{aligned}
& \dot{\tilde{x}}_{\mathrm{INV}}=A \widetilde{x}_{\mathrm{INV}}+B_{1}\left[\Delta v_{s D Q}\right]+B_{2}[\Delta w], \\
& {\left[\Delta i_{s D Q}\right]=C \widetilde{x}_{\mathrm{INV}},}
\end{aligned}
$$


where

$\dot{\tilde{x}}_{\mathrm{INV}}=\left[\begin{array}{llll}\dot{\vec{x}}_{\mathrm{INV} 1} & \dot{\tilde{x}}_{\mathrm{INV} 2} & \ldots & \dot{\tilde{x}}_{\mathrm{INV} n}\end{array}\right]^{\mathrm{T}}$,

$A=\operatorname{diag}\left[\begin{array}{llll}A_{1} & A_{2} & \ldots & A_{n}\end{array}\right]$,

$B_{1}=\left[\begin{array}{c}B_{11} \\ B_{12} \\ \vdots \\ B_{1 n}\end{array}\right], B_{2}=\left[\begin{array}{c}B_{21} \\ B_{22} \\ \vdots \\ B_{2 n}\end{array}\right]$,

$C=\operatorname{diag}\left[\begin{array}{llll}C_{1} & C_{2} & \ldots & C_{n}\end{array}\right]$

\subsection{Network model}

Here, a distribution grid with $k$ lines and $l$ node is considered. The model of the $i^{\text {th }}$ line connected between nodes $j$ and $k$ is expressed in Eq. (18), which is built on the common reference frame.

$\left[\Delta \dot{i}_{\text {line } D Q}\right]=A_{\text {net } i}\left[\Delta i_{\text {line } D Q}\right]+B_{\text {net } 1 i}\left[\begin{array}{c}\cdots \\ \Delta v_{s j D Q} \\ \cdots \\ \Delta v_{s k D Q} \\ \cdots\end{array}\right]+B_{\text {net } 2 i}[\Delta w]$,

where

$$
\begin{aligned}
& B_{\text {net } 1 i}=\frac{1}{L}\left[\begin{array}{ccccccc}
\cdots & \frac{1}{l_{\text {line } i}} & 0 & \cdots & -\frac{1}{l_{\text {line } i}} & 0 & \cdots \\
\cdots & 0 & \frac{1}{l_{\operatorname{line} i}} & \cdots & 0 & -\frac{1}{l_{\text {line } i}} & \cdots
\end{array}\right]_{2 \times(2 l)}, \\
& A_{\text {net } i}=\left[\begin{array}{cc}
-\frac{r_{\text {line } i}}{l_{\text {line } i}} & w_{0} \\
-w_{0} & -\frac{r_{\text {line } i}}{l_{\text {line } i}}
\end{array}\right], \\
& B_{\text {net } 2 i}=\left[\begin{array}{c}
I_{\text {line } i Q 0} \\
-I_{\text {line } i D 0}
\end{array}\right],
\end{aligned}
$$

where the $l_{\text {line } i}$ and $r_{\text {line } i}$ are the inductance and resistance per $\mathrm{km}$ of the distribution line, and $L$ is the length of the distribution line.

Hence, the model of a distribution grid with $k$ lines and $l$ node is given by

$$
\left[\Delta \dot{i}_{\text {line } D Q}\right]=A_{\text {net }}\left[\Delta i_{\text {line } D Q}\right]+B_{\text {net1 }}\left[\Delta v_{s D Q}\right]+B_{\text {net } 2}[\Delta w],
$$

where

$$
\begin{aligned}
& {\left[\Delta i_{\text {line } D Q}\right]=\left[\begin{array}{llll}
\Delta i_{\text {line } D Q} & \Delta i_{\text {line } 2 D Q} & \cdots & \Delta i_{\text {line } k D Q}
\end{array}\right]^{\mathrm{T}},} \\
& {\left[\Delta v_{s D Q}\right]=\left[\begin{array}{llll}
\Delta v_{s 1 D Q} & \Delta v_{s 2 D Q} & \cdots & \Delta v_{s l D Q}
\end{array}\right]^{\mathrm{T}},} \\
& A_{\text {net }}=\left[\begin{array}{cccc}
A_{\text {net1 }} & 0 & \cdots & 0 \\
0 & A_{\text {net } 2} & \cdots & 0 \\
\cdots & \cdots & \cdots & \cdots \\
0 & 0 & \cdots & A_{\text {net } k}
\end{array}\right]_{2 k \times 2 k}
\end{aligned}
$$

$$
B_{\text {net1 }}=\frac{1}{L}\left[\begin{array}{c}
B_{\text {net1 } 1} \\
B_{\text {net12 }} \\
\vdots \\
B_{\text {net } 1 l}
\end{array}\right]_{2 k \times 2 l}, B_{\text {net2 }}=\left[\begin{array}{c}
B_{\text {net21 }} \\
B_{\text {net22 }} \\
\vdots \\
B_{\text {net } 2 k}
\end{array}\right]_{2 k \times l}
$$

Remark: Although the model of the distribution grid is similar to [24], the distribution grid model in [24] does not consider the parameters of the length of distribution line. The model in (19) introduces the variable $L$, which represents the length of distribution grid to consider the relationship between length of distribution line and system stability when many DGs are connected into distribution power system.

\subsection{Loads model}

Although there are many types of load in this network, a general RL load is considered in this paper. The equations of the RL load connected at the $i^{\text {th }}$ node are $\left[\Delta \dot{i}_{\text {load } i D Q}\right]=A_{\text {load } i}\left[\Delta i_{\text {load } i D Q}\right]+B_{\text {loadl } i}\left[\Delta v_{s i D Q}\right]+B_{\text {load } 2 i}[\Delta w]$,

where

$$
\begin{aligned}
& A_{\text {load } i}=\left[\begin{array}{ccc}
-\frac{R_{\text {load } i}}{L_{\text {load } i}} & w_{0} \\
-w_{0} & -\frac{R_{\text {load } i}}{L_{\text {load } i}}
\end{array}\right], \\
& B_{\text {load } 1 i}=\left[\begin{array}{cccc}
\cdots & \frac{1}{L_{\text {load } i}} & 0 & \cdots \\
\cdots & 0 & \frac{1}{L_{\text {load } i}} & \cdots
\end{array}\right]_{2 \times 2 l}, \\
& B_{\text {load } 2 i}=\left[\begin{array}{c}
I_{\text {load } i Q 0} \\
-I_{\text {load } i Q 0}
\end{array}\right] .
\end{aligned}
$$

Hence, for a network with s load points, the model of loads is given by

$$
\left[\Delta \dot{i}_{\text {load } D Q}\right]=A_{\text {load }}\left[\Delta i_{\text {load } D Q}\right]+B_{\text {loadl }}\left[\Delta v_{s D Q}\right]
$$

where

$\left[\Delta i_{\text {load } D Q}\right]=\left[\begin{array}{llll}\Delta i_{\text {load } 1 D Q} & \Delta i_{\text {load } 2 D Q} & \cdots & \Delta i_{\text {load } S D Q}\end{array}\right]^{\mathrm{T}}$, $\left[\Delta v_{s D Q}\right]=\left[\begin{array}{llll}\Delta v_{s 1 D Q} & \Delta v_{s 2 D Q} & \cdots & \Delta v_{s l D Q}\end{array}\right]^{\mathrm{T}}$,

$A_{\text {load }}=\left[\begin{array}{cccc}A_{\text {load } 1} & 0 & \cdots & 0 \\ 0 & A_{\text {load } 1} & \cdots & 0 \\ \cdots & \cdots & \cdots & \cdots \\ 0 & 0 & \cdots & A_{\text {load } s}\end{array}\right]_{2 s \times 2 s}$,

$B_{\text {load } 1 i}=\left[\begin{array}{cccc}\cdots & \frac{1}{L_{\mathrm{load} i}} & 0 & \cdots \\ \cdots & 0 & \frac{1}{L_{\mathrm{load} i}} & \cdots\end{array}\right]_{2 \times 2 l}$, 


$$
B_{\text {load } 1}=\left[\begin{array}{c}
B_{\text {load11 }} \\
B_{\text {load12 }} \\
\cdots \\
B_{\text {load } 1 s}
\end{array}\right]_{2 s \times 2 l}, B_{\text {load2 }}=\left[\begin{array}{c}
B_{\text {load21 }} \\
B_{\text {load22 }} \\
\cdots \\
B_{\text {load2s }}
\end{array}\right]_{2 s \times l} .
$$

\subsection{Multi-DGs system model}

Once the model of DG, network and loads is accomplished, the model of multi-DGs system can be obtained by combining each part models. In order that the node voltage is well defined, the virtual resistance $\left(r_{\mathrm{N}}\right)$ is introduced between the network node and ground. Then the node voltage can be written in terms of currents, and given by

$V_{s i D Q}=r_{\mathrm{N}}\left(i_{s i D Q}-i_{\text {load } i D Q}+i_{\text {line } i, j D Q}\right)$.

Therefore the node voltage equation of multi-DGs system can be expressed as

$\left[V_{s D Q}\right]=$

$=\boldsymbol{R}_{\mathrm{N}}\left(\boldsymbol{M}_{\mathrm{INV}}\left[\Delta i_{s D Q}\right]+\boldsymbol{M}_{\text {load }}\left[\Delta i_{\text {load } D Q}\right]+\boldsymbol{M}_{\text {net }}\left[\Delta i_{\text {line } D Q}\right]\right)$.

where, the matrix $\boldsymbol{R}_{\mathrm{N}}$ is of size $2 l \times 2 l$, whose diagonal elements are equal to $r_{\mathrm{N}}$. The $\boldsymbol{M}_{\mathrm{INV}}$ is a $2 l \times 2 n$ matrix. If the $j^{\text {th }} \mathrm{DG}$ is connected to the ith node, then the $\boldsymbol{M}_{\mathrm{INV}}(i, j)$ is 1 , else is 0 . Similarly, the $\boldsymbol{M}_{\text {load }}$ is of size $2 l \times 2 s$ matrix. If the $j^{\text {th }}$ load is connected to the ith node, then $\boldsymbol{M}_{\text {load }}(i, j)$ is -1 , otherwise it is 0 .
Matrix $\boldsymbol{M}_{\text {net }}$ of size $2 l \times 2 k$ maps the connecting lines onto the network nodes. Here, if $i^{\text {th }}$ node is connected with the $j^{\text {th }}$ line, and the current flow into the $i^{\text {th }}$ node, then the $\boldsymbol{M}_{\text {net }}(i, j)$ is 1 , else is -1 .

Now, the complete multi-DGs system model (as given in (24)) can be obtained by using the individual subsystem models given by (14), (15), (19), (21) and (23)

$$
\left[\begin{array}{c}
\Delta \dot{\tilde{x}}_{\text {INV }} \\
\Delta \dot{i}_{\text {line } D Q} \\
\Delta \dot{i}_{\text {load } D Q}
\end{array}\right]=\boldsymbol{A}_{m g}\left[\begin{array}{c}
\Delta x_{\text {INV }} \\
\Delta i_{\text {line } D Q} \\
\Delta i_{\text {load } D Q}
\end{array}\right]+\boldsymbol{B}_{m g}[\Delta w],
$$

where

$$
\begin{aligned}
\boldsymbol{A}_{m g} & =\left[\begin{array}{ccc}
\boldsymbol{A}_{\mathrm{INV}}+B_{1} \boldsymbol{R}_{\mathrm{N}} \boldsymbol{M}_{\mathrm{INV}} C & B_{1} \boldsymbol{R}_{\mathrm{N}} \boldsymbol{M}_{\text {net }} & B_{1} \boldsymbol{R}_{\mathrm{N}} \boldsymbol{M}_{\text {load }} \\
B_{\text {netl }} \boldsymbol{R}_{\mathrm{N}} \boldsymbol{M}_{\text {INV }} C & \boldsymbol{A}_{\text {net }}+B_{\text {nett }} \boldsymbol{R}_{\mathrm{N}} \boldsymbol{M}_{\text {net }} & B_{\text {netl } 1} \boldsymbol{R}_{\mathrm{N}} \boldsymbol{M}_{\text {load }} \\
B_{\text {loadl }} \boldsymbol{R}_{\mathrm{N}} \boldsymbol{M}_{\text {INV }} C & B_{\text {loadl }} \boldsymbol{R}_{\mathrm{N}} \boldsymbol{M}_{\text {net }} & \boldsymbol{A}_{\text {load }}+B_{\text {loadl }} \boldsymbol{R}_{\mathrm{N}} \boldsymbol{M}_{\text {load }}
\end{array}\right] \\
\boldsymbol{B}_{m g} & =\left[\begin{array}{lll}
B_{2} & B_{\text {net2 }} & B_{\text {load } 2}
\end{array}\right]^{\mathrm{T}} .
\end{aligned}
$$

And the matrix $\boldsymbol{A}_{\mathrm{mg}}$ is shown at the bottom of the page.

\section{Multi-DGs system design according the model}

An important consideration when designing a multiDGs system is system stability. According to Eq. (24), we can analyse the system stability quantitatively, but it can be seen that the matrices $\boldsymbol{A}_{\mathrm{mg}}$ and $\boldsymbol{B}_{\mathrm{mg}}$ can vary from system to system. It means that the behaviours of any system would be different if the systems' structures are different. It is necessary to propose a process of system stability analysis according to the model of multi-DGs system, as shown in Fig. 7.

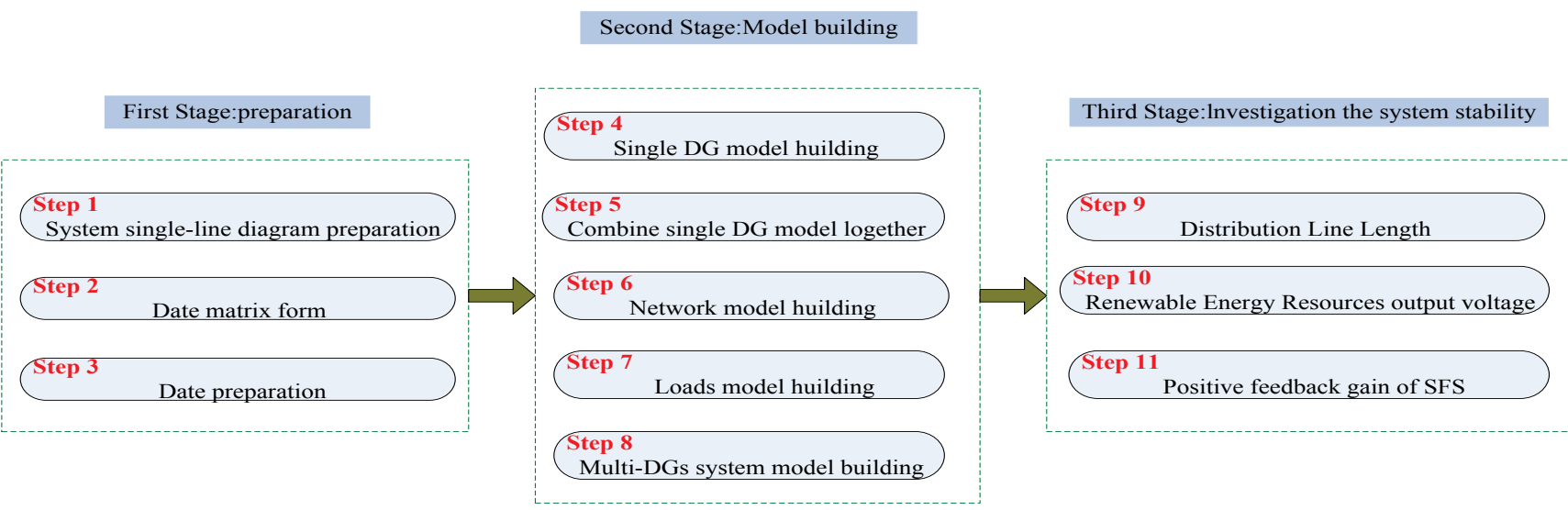

Figure 7 The process of system stability analysis

\section{A. First Stage: preparation}

This stage is mainly devoted to the distribution network simplify, which prepare for next stage. It is regarded as the basis for the fellow stage analysis.

Step 1) System single-line diagram preparation:

The first step is to prepare a single-line diagram of the study system, as shown in Fig. 8.

Step 2) Date matrix form:

Any multi-DGs system can be represent by Graph Theory. This step is used to identify the connection of network, such as $\boldsymbol{M}_{\mathrm{INV}}, \boldsymbol{R}_{\mathrm{N}}, M_{\text {load }}, M_{\text {net }}$.

Step 3) Date preparation:
This step deals with the collection the system parameters, like distribution line resistance and reactance, LCL filters, controller interfaces and loads

\section{B. Second Stage: Model building}

This stage is used to build the analysis model of multi-DGs system.

Step 4) Single DG model building:

In Section 3.1, the model of single DG with SFS antiislanding protection is built. As a result, based on the collection parameters in step 3 the model is completed according equation (13).

Step 5) Combine single DG model together: 
Due to the study cases are the multi-DGs system, the single DG model should be combined together. The operation of combining is based on Eq. (16) and (17).

Step 6) Network model building:

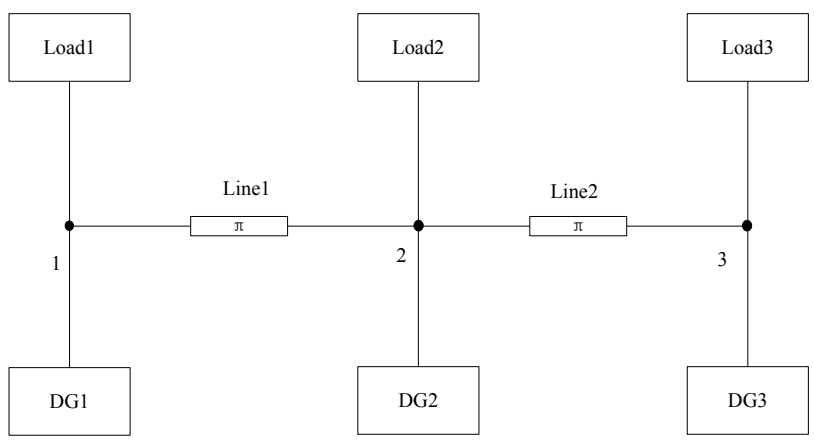

Figure 8 The multi-DGs system's structure of the study

This step builds the network model according to Eq. (19).

Step 7) Loads model building:

This step builds the load model according to Eq. (21). In practice, if there are other type loads, for the veracity of the loads model, other types of load models should be considered.

Step 8) Multi-DGs system model building:

This step combines the section model built in steps 4 to 7 to complete the multi-DGs system according to equation (24).

\section{Third Stage: Investigation of the system stability}

This stage is used to quantitatively analyse the factors influencing stability in multi-DGs systems, which are the length of distribution line, positive feedback with SFS and renewable resource output voltage.

Step 9) Distribution line length:

This step considers the effect of distance between any DGs on system stability.

Step 10) Renewable energy resources output voltage:

This step considers the effect of Renewable Energy Resources output voltage on the system stability.

Step 11) Positive feedback gain of SFS:

This step is for optimizing positive feedback gain to realize the biggest gain to anti-islanding protection when the system is in a stable condition.

\section{Simulation results}

As an example to verify the improved model, a multiDGs system with 3DGs, 3 nodes, 3 loads and 2 transmission lines as shown in Fig. 8, is analysed according to the process described in Section 4. The data of the system can be seen in Tabs. 1 and 4 in Appendix A. The crux of this work presented here focuses on analysing the relationship between system parameters and stability.

\subsection{Case 1: Distribution line length}

As DGs are installed along the distribution line, the different lengths of lines have different impacts (e.g. the loss of active and reactive power) on system. Fig. 9 and Fig. 10 show the locus of the eigenvalues of distribution line 1 and line 2 respectively.

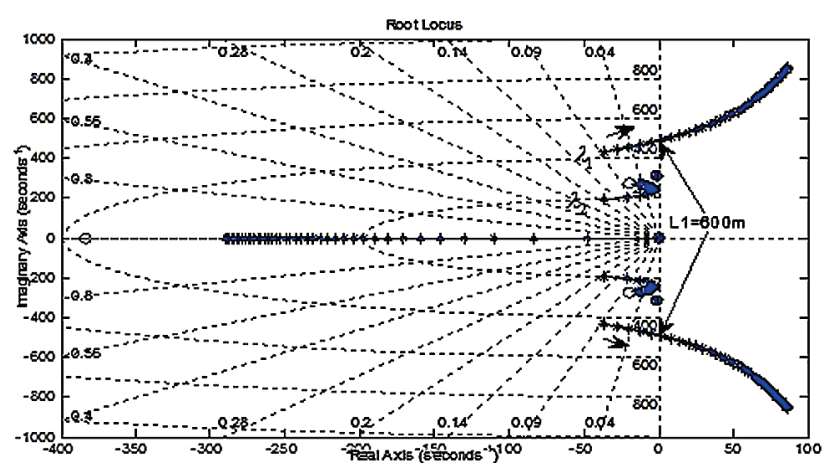

Figure 9 The eigenvalues locus for distribution line 1

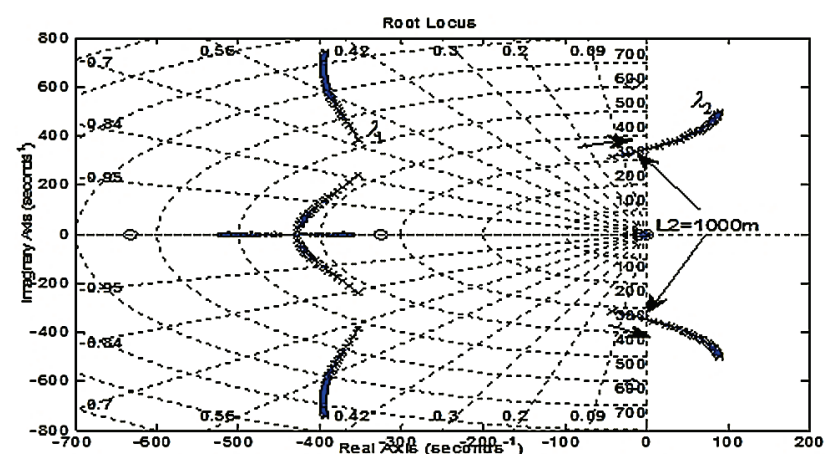

Figure 10 The eigenvalues locus for distribution line 2

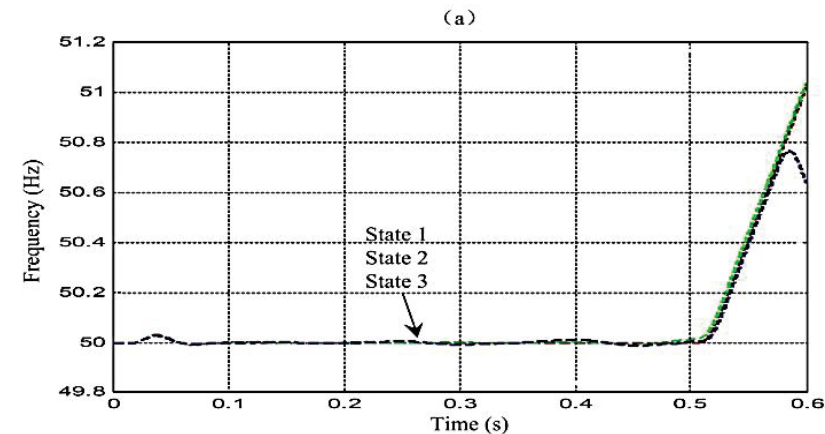

(b)

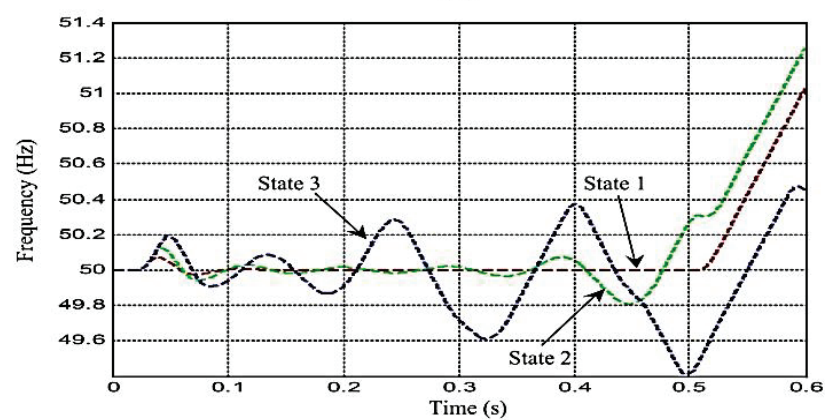

(c)

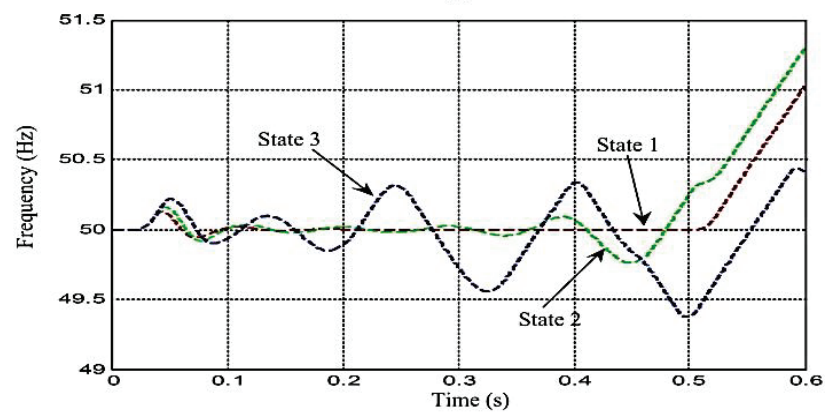

Figure 11 The terminal frequency responses of DGs for distribution line 1 in case 1: (a) Terminal frequency response of DG1, (b) Terminal frequency response of DG2, (c) Terminal frequency response of DG3. The islanding condition is applied at $t=0,5 \mathrm{~s}$. 
It can be seen that the length of lines have a significant effect on system stability.

Fig. 9 and 10 illustrate the motion towards the imaginary axis of domain eigenvalues pairs as the lengths of distribution lines are increased. Although positive feedback gain could adjust the system stability, it also could affect the performance of SFS. Fig. 9 and 10 also show that high length of distribution line would make the system lose stability, with instability occurring at $600 \mathrm{~m}$ and $1000 \mathrm{~m}$ respectively, represented as $L_{1 \max }$ and $L_{2 \max }$. For $L_{1}<L_{1 \max }, L_{2}<L_{2 \max }$, the length of the distribution line can be annotated as $L_{1 l}$ and $L_{1 l}$, with a corresponding stability margin of 1 . For example, when $L_{1}=400 \mathrm{~m}$, it can be expressed as $L_{1}=200$.

The two cases are considered here to verify the system stability analysis result obtained from Fig. 9 and 10 through simulation.

\subsection{Case 2: Simulation results validating the analysis of the distribution line 1}

In this case, three different lengths of distribution line 1 are given to confirm the analysis result. The length of distribution line 1 in states $1 \div 3$ can be expressed as $L_{1}=400, L_{1}=100$ and $L_{1}=-400$, while the length of distribution line 2 is $L_{2}=200 \mathrm{~m}$ in all states. The negative of stability margin 1 means the system loses stability.

The simulation results are shown in Fig. 11. In the first state, the terminal frequency responses of DGs are stable, while in the second state and third states, the terminal frequency responses of DG1 are the same as in state 1 , but the terminal frequency responses of DG2 and DG3 begin oscillating because increasing the length of distribution line 1 makes the stability margin 1 reduce from 400 to -400 . It is worth noting that the DG2 and DG3 have already lost stability state 3 , and the stability margin of $L_{1}$ is -400 . Once the islanding condition occurs at 0,5 $\mathrm{s}$, the SFS can stop the DG less than 10 cycles at $50 \mathrm{~Hz}$ in all states.

\subsection{Case 3: Simulation results validating the analysis of the distribution line 2}

In this case, the simulation operations are the same as with case 1 . The length of distribution line 2 in states $1 \div 3$ can be expressed as $L_{2}=800, L_{2}=0$ and $L_{2}=-500$, and the length of distribution line 1 is $L_{1}=200 \mathrm{~m}$ in all states. We validate the analysis of the distribution line 2 .

The simulation results are shown in Fig. 12. The frequency responses of DG1 are the same compared with Fig. 11a. It is because the DG1 is connected to the distribution grid directly, and changing the length of distribution lines has little influence on the frequency responses of DG1. The frequency responses of DG2 have little oscillation owing to the length of distribution line 2 being increased, and do not influence the state of system operation.

However, the frequency responses of DG3 are unstable when the distribution line 2 is in state 3 , and the stability margins are 0 and -500 respectively.

Moreover, according to the analysis and simulation results, the SFS detection time is affected by increasing the distribution line, shown in Figs. 11 and 12. This indicates that the system parameters not only affect the system stability, but also affect the SFS detection time. Therefore, further research is needed to model and analyse the relationship between length distribution line and SFS detection time.

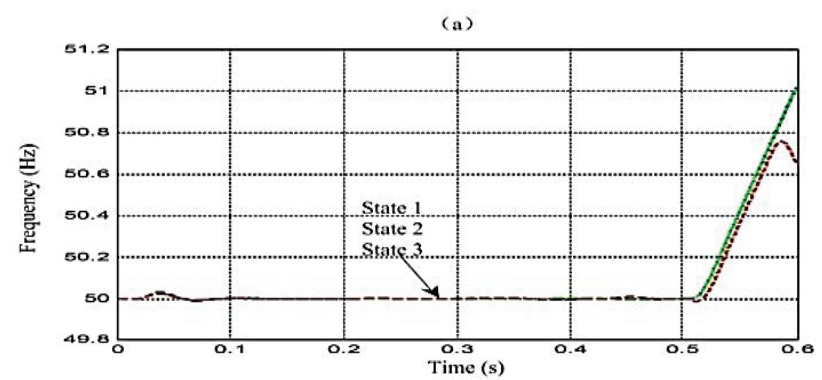

(b)

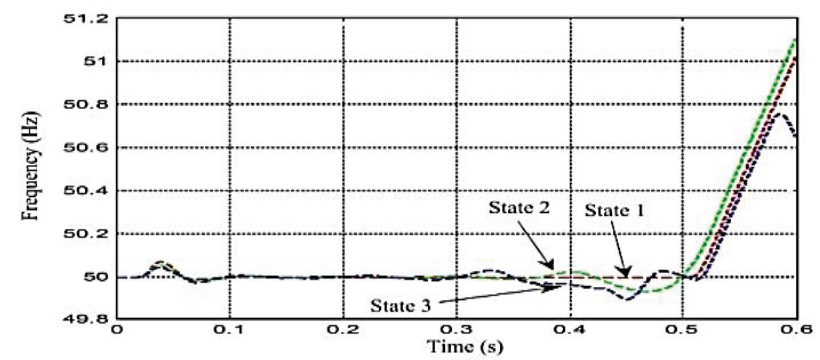

(c)

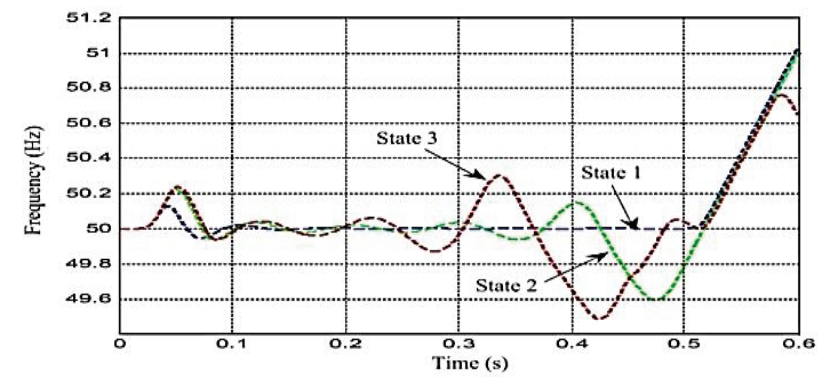

Figure 12 The terminal frequency responses of DGs for distribution line 2 in case 2: (a) Terminal frequency response of DG1, (b) Terminal frequency response of DG2, (c) Terminal frequency response of DG3. The islanding condition is applied at $t=0,5 \mathrm{~s}$.

\subsection{DC voltage of DG}

In fact, there are many types of DG system, whose DC voltages are different. So it is necessary to analyse the relationship between DG's DC voltage and system stability. Fig. 13 shows the locus of the eigenvalues of DG's DC voltage. It can be seen that the DC voltages of DGs have a significant effect on the system stability.

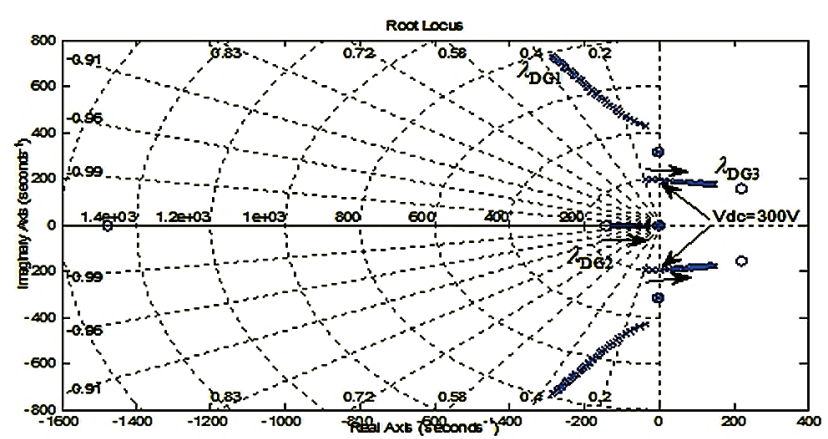

Figure 13 The eigenvalues locus of DG's DC voltage 
From the figure it can be seen that with the increase of DC voltage, the domain eigenvalues pairs move to the imaginary axis, which means that the system tends to become unstable, just like analysis of the distribution line. The threshold value of the DC voltage of DG3 is $300 \mathrm{~V}$, represented as $V_{d c 3 \max }$, while the other two DGs can retain stability under this situation. For $V_{\mathrm{dc}}<V_{d c \max }$, the $\mathrm{DC}$ voltage of $\mathrm{DG}$ can be annotated as $V_{d c \mathrm{~m}}$, with a corresponding stability margin of $\mathrm{m}$. It should be noted that changing one DG's DC voltage, the stability margins of the other DGs in the system would be reduced; for example if the DC voltage of DG2 changes from $300 \mathrm{~V}$ to $700 \mathrm{~V}$, the stability margin of DG1 is reduced from $100 \mathrm{~V}$ to $20 \mathrm{~V}$.

\subsection{Simulation results validating the analysis of the DC voltage}

In this case, the two operation states are designed to validate the analysis of the DC voltage of DG. In state 1, the DC voltage of DG3 is $400 \mathrm{~V}$, and can be expressed as $V_{d c 3}=-100$. In state 2 , the DC voltage of DG3 is $250 \mathrm{~V}$, and can be expressed as $V_{d c}=350$. The system's other parameters are maintained as the same as shown in Appendix A.

Fig. 14 and Fig. 15 display the simulation results. Like simulation cases 1 and 2 , once the islanding condition occurs at $0,5 \mathrm{~s}$, the SFS can stop the DG less than two cycles at $50 \mathrm{~Hz}$ in all states. Obviously, the stability of DG3 cannot maintain stability under state 1 as the DG's DC voltage is $400 \mathrm{~V}$, which is greater than $300 \mathrm{~V}$. If we reduce the DC voltage to under $300 \mathrm{~V}$ (e.g. $250 \mathrm{~V})$, then the DG3 becomes stable. Beyond that, the performance of DG2 improves, as can be seen by comparing Fig. 14 and Fig. 15.

However, the eigenvalues in Figs. 9, 10 and 11 are specific to the example of multi-DGs system, due to the matrices $\boldsymbol{A}_{\mathrm{mg}}$ and $\boldsymbol{B}_{\mathrm{mg}}$ which can vary from system to system. If there is a new system to analyse, it can be carried out as described in Section 4.

\section{Conclusion}

The investigations reported in this paper show that the length of distribution lines and DC voltage of DG have a significant influence on the stability of a multiDGs system. In order to achieve a quantitative analysis of the influences on a multi-DGs system, the mode of multiDGs system is improved based on previous research.

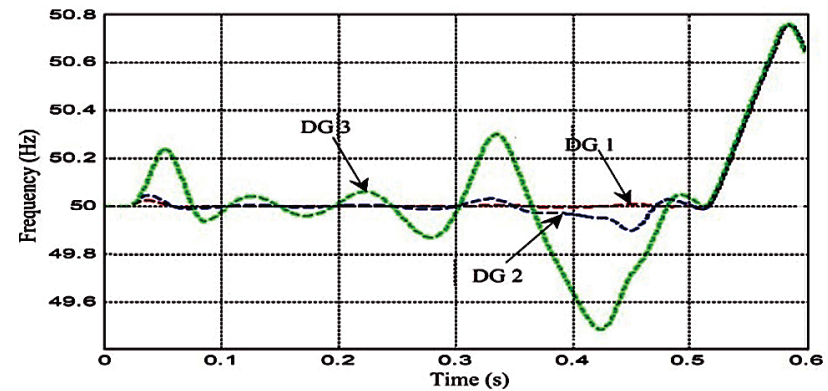

Figure 14 The terminal frequency of DGs under state 1. The islanding condition is applied at $t=0,5 \mathrm{~s}$.

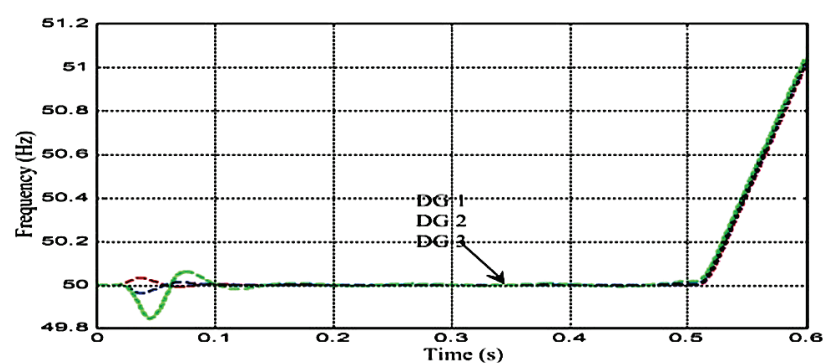

Figure 15 The terminal frequency of DGs under state 2. The islanding condition is applied at $t=0,5 \mathrm{~s}$.

The model was analysed in terms of the system's locus of the eigenvalues. With the help of this analysis, the threshold value of the influencing parameters can be obtained and some suggestions for designers and engineers of renewable energy system can be obtained as follows.

Analysis and simulation of the length of distribution lines show that they can cause instability to the multi-DGs system. In principle, in order to promote the performance of system, the length of the distribution line is as short as possible.

As changing the length of distribution lines gives the downstream DGs loss of stability, the upstream DGs have little effect. So when adjusting the length of distributed lines, the first choice is to adjust the end of line in the multi-DGs system, as in this way the scope of instability in the system is least.

Analysis and simulation on the DC voltages of DGs show that the terminal frequency responses of DGs will oscillate if the DC voltages are too high.

Reducing the DC voltages of DGs can not only improve their performance, but also can promote the performance of the surrounding DGs.

The suggestions obtained according to the model were verified by simulation. It was observed that the simulation results are consistent with the model analysis results.

In addition, a new problem was found, i.e. that the system parameters also can affect the SFS detection time. The research about this problem needs to be done in any future work.

In conclusion, the results verifying the proposed method can be efficiently implemented for the actual multi-DGs system and can enable us to discover the threshold value of system parameters, which affect the system stability. Hence system stability analysis is important for multi-DGs system design. So the proposed method is expected to provide an effective approach to planning and design for implementation in the renewable energy field, while the suggestions made in this paper are useful for the designers and engineers of renewable energy system.

\section{References}

[1] Liserre, M.; Sauter, T.; Hung, J. Y. Future energy systems: Integrating renewable energy sources into the smart power grid through industrial electronics. // Industrial Electronics Magazine, IEEE. 4, 1(2010), pp. 18-37. DOI: 10.1109/MIE.2010.935861

[2] Pepermans, G.; Driesen, J.; Haeseldonckx, D. et al. Distributed generation: definition, benefits and issues. // 
Energy policy. 33, 6(2005), pp. 787-798. DOl: 10.1016/j.enpol.2003.10.004

[3] Ropp, M. E.; Begovic, M.; Rohatgi, A. Prevention of islanding in grid connected photovoltaic systems. // Progress in Photovoltaics: Research and Applications. 7, 1(1999), pp. 39-59. DOI: 10.1002/(SICl)1099159X(199901/02)7:1<39::AID-PIP246>3.0.CO;2-J

[4] Velasco, D.; Trujillo, C. L.; Garcera, G. et al. Review of anti-islanding techniques in distributed generators. // Renewable and sustainable energy reviews. 14, 6(2010), pp. 1608-1614. DOI: 10.1016/j.rser.2010.02.011

[5] Ropp, M. E.; Aaker, K.; Haigh, J. et al. Using power line carrier communications to prevent islanding. // Photovoltaic Specialists Conference, 2000. Conference Record of the Twenty-Eighth IEEE. IEEE, 2000, pp. 1675-1678.

[6] Zeineldin, H. H.; El-Saadany, E. F.; Salama, M. M. A. Impact of DG interface control on islanding detection and nondetection zones. // Power Delivery, IEEE Transactions on. 21, 3(2006), pp. 1515-1523. DOl: 10.1109/TPWRD.2005.858773

[7] Zeineldin, H. H.; Salama, M. M. A. Impact of load frequency dependence on the NDZ and performance of the SFS islanding detection method. // Industrial Electronics, IEEE Transactions on. 58, 1(2011), pp. 139-146. DOI: 10.1109/TIE.2009.2033482

[8] Alaboudy, A. H. K.; Zeineldin, H. H. Islanding detection for inverter-based DG coupled with frequency-dependent static loads. // Power Delivery, IEEE Transactions on. 26, 2(2011), pp. 1053-1063. DOI: 10.1109/TPWRD.2010.2087042

[9] Wang, X.; Freitas, W.; Dinavahi, V. et al. Investigation of positive feedback anti-islanding control for multiple inverter-based distributed generators. // Power Systems, IEEE Transactions on. 24, 2(2009), pp. 785-795. DOl: 10.1109/TPWRS.2008.2007002

[10] Ghaderi, A.; Kalantar, M. Investigation of influential factors on passive islanding detection methods of inverter based distributed generation. // Power Electronics, Drive Systems and Technologies Conference (PEDSTC), 2011 $2^{\text {nd }}$. IEEE, (2011), pp. 217-222.

[11] Pogaku, N.; Prodanovic, M.; Green, T. C. Modeling, analysis and testing of autonomous operation of an inverterbased microgrid. // Power Electronics, IEEE Transactions on. 22, 2(2007), pp. 613-625. DOI: 10.1109/TPEL.2006.890003

[12] Barklund, E.; Pogaku, N.; Prodanovic, M.; HernandezAramburo, C.; Green, T. C. Energy management in autonomous mocrogrid using stability-constrained droop control of inverters. // Power Electronics, IEEE Transactions on. 23, 5(2008), pp. 2346-2352, DOI: 10.1109/TPEL.2008.2001910

[13] Wen Yuan, H.; Tao, Z.; Xiao Yu, W. Investigation of multi-inverter distributed generation resident Sandia frequency shift anti-islanding method. // Advanced Power System Automation and Protection (APAP), 2011 International Conference on. IEEE. 2, (2011), pp. 935-939.

[14] Afzalan, M.; Taghikhani, M. A. Placement and Sizing of DG Using PSO\&HBMO Algorithms in Radial Distribution Networks. // International Journal of Intelligent Systems and Applications (IJISA). 4, 10(2012), p. 43. DOl: 10.5815/ijisa.2012.10.05

[15] Majumder, R. Modeling, stability analysis and control of microgrid. // PhD Thesis, Queensland University of Technology, Queensland, Australia, February 2010, p. 156.

\section{Authors' addresses}

Weihua Chen, PhD

Liaoning Technical University

Liaoning Huludao 125105, China

E-mail: fxlgd@163.com

\section{Xiaoheng Yan, PhD}

Liaoning Technical University

Liaoning Huludao 125105, China

E-mail: 3350464@163.com

\section{Jishen Pen}

Liaoning Technical University

Liaoning Fuxin 123000, China

E-mail: pengjishen@163.com

Zhongjian Zhao

China Petroleum Liaohe Equipment Company

Liaoning Panjin 124000, China

E-mail:470088702@qq.com

\section{Appendix A}

Table 1 Distribution line parameters

\begin{tabular}{|l|c|c|}
\hline \multicolumn{1}{|c|}{ Parameters } & Line 1 & Line 2 \\
\hline Resistance $(\Omega / \mathrm{km})$ & 0,2568 & 0,2568 \\
\hline Inductance $(\mathrm{mH} / \mathrm{km})$ & 2 & 2 \\
\hline Capacitance $(\mathrm{pF} / \mathrm{km})$ & 8,6 & 8,6 \\
\hline
\end{tabular}

Table 2 Initial conditions for multi-DGs system

\begin{tabular}{|c|c|c|c|}
\hline Parameters & Value & $\begin{array}{c}\text { Parameter } \\
\mathrm{S}\end{array}$ & Value \\
\hline$I_{s d}$ & {$\left[\begin{array}{lll}25 & 25 & 25\end{array}\right]$} & $I_{s q}$ & {$\left[\begin{array}{lll}0 & -0,4 & 1,25\end{array}\right]$} \\
\hline$V_{p d}$ & {$\left[\begin{array}{llll}220 & 220 & 220\end{array}\right]$} & $\frac{\mathrm{sq}}{V_{\mathrm{pq}}}$ & {$\left[\begin{array}{lll}0 & 0 & 0\end{array}\right]$} \\
\hline$I_{l d}$ & {$\left[\begin{array}{llll}25 & 25 & 25\end{array}\right]$} & $I_{\mathrm{lq}}$ & {$\left[\begin{array}{lll}0 & -1 & 0,45\end{array}\right]$} \\
\hline$V_{s d}$ & {$\left[\begin{array}{llll}22 & 220 & 220\end{array}\right]$} & $V_{\mathrm{sq}}$ & {$\left[\begin{array}{lll}5 & -5 & 0\end{array}\right]$} \\
\hline$\omega_{0}$ & 314 & $\delta_{0}$ & {$\left[\begin{array}{lll}0 & 0 & 0\end{array}\right]$} \\
\hline$I_{\text {linel } d}$ & $-4,8$ & $I_{\text {linel } q}$ & 0,4 \\
\hline$I_{\text {line2 } d}$ & 5 & $I_{\text {line2 } q}$ & $-1,2$ \\
\hline
\end{tabular}

Table 3 Parameters for DG

\begin{tabular}{|c|c|c|c|}
\hline Parameters & Value & Parameters & Value \\
\hline$L_{f}$ & $1,35 \mathrm{mH}$ & $V_{d c}$ & $400 \mathrm{~V}$ \\
\hline$C_{f}$ & $50 \mu \mathrm{F}$ & $L_{c}$ & $0,35 \mathrm{mH}$ \\
\hline$R_{f}$ & $0,1 \Omega$ & $R_{c}$ & $0,03 \Omega$ \\
\hline$K_{p i}$ & 80 & $K_{i i}$ & 200 \\
\hline$\omega_{0}$ & $100 \pi$ & $K_{p v}$ & $2,5 \times 10^{-3}$ \\
\hline$c_{f 0}$ & 0,05 & $k_{1}$ & 0,5 \\
\hline$k_{2}$ & 0,05 & $k_{3}$ & 0,01 \\
\hline
\end{tabular}

Table 4 Loads Parameters

\begin{tabular}{|l|c|c|c|}
\hline \multicolumn{1}{|c|}{ Parameters } & Load 1 & Load 2 & Load 3 \\
\hline Resistance & $5 \Omega$ & $5 \Omega$ & $5 \Omega$ \\
\hline Inductance & $7,65 \mathrm{mH}$ & $7,65 \mathrm{mH}$ & $7,65 \mathrm{mH}$ \\
\hline Capacitance & $1300 \mu \mathrm{F}$ & $1300 \mu \mathrm{F}$ & $1300 \mu \mathrm{F}$ \\
\hline Quality factor & 2 & 2 & 2 \\
\hline
\end{tabular}

